\title{
Structural Determinants of Transmission at Large Hippocampal Mossy Fiber Synapses
}

\author{
Astrid Rollenhagen, ${ }^{1,4 *}$ Kurt Sätzler, ${ }^{2 *}$ E. Patricia Rodríguez, ${ }^{2}$ Peter Jonas, ${ }^{3}$ Michael Frotscher ${ }^{4}$ and \\ Joachim H. R. Lübke ${ }^{1,4}$ \\ ${ }^{1}$ Institute of Neuroscience and Biophysics INB-3, Research Centre Jülich, D-52425 Jülich, Germany, ${ }^{2}$ School of Biomedical Sciences, University of Ulster, \\ Coleraine, County Londonderry BT52 1SA, United Kingdom, and Institutes of ${ }^{3}$ Physiology and ${ }^{4}$ Anatomy and Cell Biology, Albert Ludwigs University of \\ Freiburg, D-79104 Freiburg, Germany
}

Synapses are the key elements for signal processing and plasticity in the brain. To determine the structural factors underlying the unique functional properties of the hippocampal mossy fiber synapse, the complete quantitative geometry was investigated, using electron microscopy of serial ultrathin sections followed by computer-assisted three-dimensional reconstruction. In particular, parameters relevant for transmitter release and synaptic plasticity were examined. Two membrane specializations were found: active zones (AZs), transmitter release sites, and puncta adherentia, putative adhesion complexes. Individual boutons had, on average, 25 AZs (range, 7-45) that varied in shape and size (mean, $0.1 \mu \mathrm{m}^{2}$; range, $0.07-0.17 \mu \mathrm{m}^{2}$ ). The mean distance between individual AZs was $0.45 \mu \mathrm{m}$. Mossy fiber boutons and their target structures were mostly ensheathed by astrocytes, but fine glial processes never reached the active zones. Two structural factors are likely to promote synaptic cross talk: the short distance between AZs and the absence of fine glial processes at AZs. Thus, synaptic cross talk may contribute to the efficacy of hippocampal mossy fiber synapses. On average, a bouton contained 20,400 synaptic vesicles; $\sim 900$ vesicles were located within $60 \mathrm{~nm}$ from the active zone, $\sim 4400$ between 60 and $200 \mathrm{~nm}$, and the remaining beyond $200 \mathrm{~nm}$, suggesting large readily releasable, recycling, and reserve pools. The organization of the different pools may be a key structural correlate of presynaptic plasticity at this synapse. Thus, the mossy fiber bouton differs fundamentally in structure and function from the calyx of Held and other central synapses.

Key words: mossy fiber; neuromodulation; synapse; synaptic transmission; synaptic plasticity; synaptic vesicle release

\section{Introduction}

The mossy fiber (MF) system is a morphologically highly complex structure. MF axons exhibit three distinct presynaptic specializations: large "giant" mossy fiber boutons (MFBs), small en passant boutons, and filopodial extensions emerging from the MFBs (Amaral and Dent, 1981; Galimberti et al., 2006). Large MFBs innervate spiny excrescences of CA3 pyramidal neurons (Blackstad and Kjaerheim, 1961; Hamlyn, 1962) and hilar mossy cells (Frotscher et al., 1994). In contrast, filopodial extensions mainly contact GABAergic interneurons in the stratum lucidum (Acsády et al., 1998), but large MFBs also directly contact the dendritic shafts of GABAergic interneurons (for review, see Frotscher et al., 2006). A single granule cell axon gives rise to $\sim 15$ large $\mathrm{MFB}$ in the $\mathrm{CA} 3$ region, and a single CA3 pyramidal neuron receives input from $\sim 50 \mathrm{MF}$ axons (Amaral et al., 1990). Thus, the morphological properties of the MF synapse are con-

\footnotetext{
Received April 30, 2007; revised July 19, 2007; accepted July 23, 2007.

This work was supported by Deutsche Forschungsgemeinschaft Sonderforschungsbereich 505 (J.H.R.L). We thank B. Joch, S. Nestel, and E. Nicksch for their excellent technical support, and Drs. Leander Söhl and Arnd Roth, who also contributed to this work. In addition, we thank Profs. J. Rettig and W. Betz for helpful discussions and for critically reading a previous version of this manuscript.

${ }^{*}$ A.R. and K.S. contributed equally to this work.

Correspondence should be addressed to Joachim H. R. Lübke, Institute of Neuroscience and Biophysics, INB-3, Research Centre Jülich, D-52425 Jülich, Germany. E-mail: j.luebke@fz-juelich.de. D0I:10.1523/JNEUROSCI.1946-07.2007

Copyright $\odot 2007$ Society for Neuroscience $\quad$ 0270-6474/07/2710434-11\$15.00/0
}

sistent with the view that it forms a powerful, but sparse, connection.

Hippocampal MF synapses show several unique transmission and plasticity properties. MF synapses are strong synapses, generating large postsynaptic currents and potentials in both CA3 pyramidal neurons and interneurons (Henze et al., 2002b; Lawrence et al., 2004). MF synapses can undergo substantial changes in synaptic strength, exhibiting marked paired pulse facilitation, frequency facilitation, posttetanic potentiation, and long-term potentiation (LTP) (Salin et al., 1996) (for review, see Nicoll and Schmitz, 2005). Finally, the properties of MF transmission are highly compartmentalized. At MF-interneuron synapses, the extent of synaptic plasticity is markedly smaller than at MF-CA3 pyramidal neuron synapses (Tóth et al., 2000). The high synaptic efficacy and plasticity may be partially explained by the organization of the pool of synaptic vesicles. Direct presynaptic recording from MFBs revealed that the releasable pool is very large with $\sim 1400$ vesicles per bouton (Geiger and Jonas, 2000; Hallermann et al., 2003). However, the structural correlates of the readily releasable pool (RRP), the recycling pool (RP), and the reserve pool have not yet been identified.

Several lines of evidence suggest that MF synapses play a key role in processing, storage, and recall of spatial information in the hippocampal network (Lisman, 1999). If granule cells fire at high frequency, synaptic efficacy and differential synaptic dynamics 

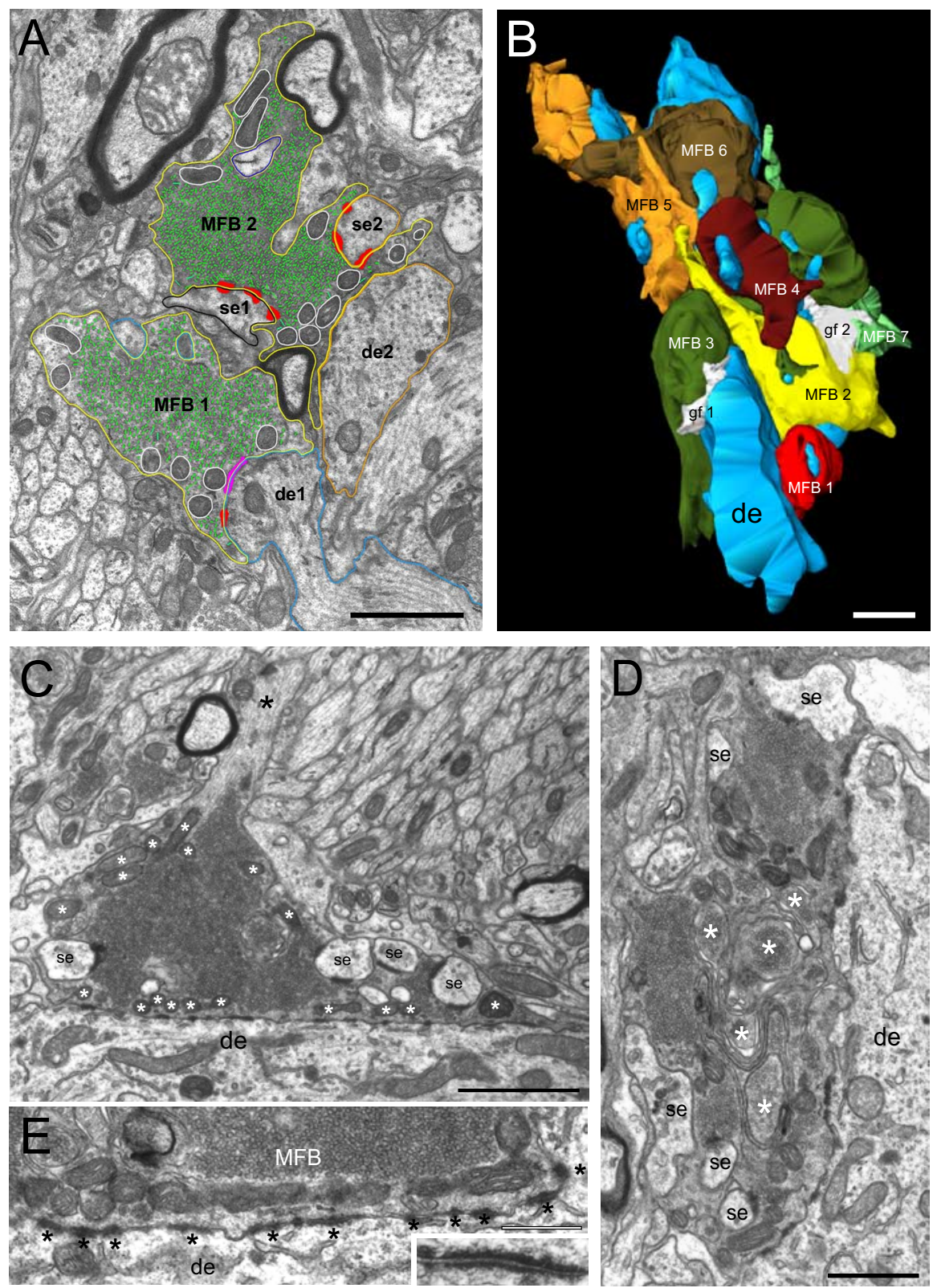

Figure 1. Complexity of the hippocampal mossy fiber system. $\boldsymbol{A}$, Electron microscopic image of two adjacent MFBs (MFB1, MFB2) taken from a P28 rat. Both MFBs outlined in yellow terminate on different dendritic segments (de1, blue contour; de2, orange contour), but preferentially on spiny excrescences (se1, black contour; se2, orange contour). AZs are given in red, PAs are given in magenta, mitochondria are given as white contours, and individual synaptic vesicles are represented by green lines. $\boldsymbol{B}$, Dense and multiple innervation of individual MFBs of different shape and size (given in various colors) on a postsynaptic target dendrite (blue) in an adult rat. Two glial fingers ( $g f 1$ and $g \mathrm{f} 2$ ) that were located between individual MFBs are depicted in white. Scale bars: $\boldsymbol{A}, \boldsymbol{B}, 1 \mu \mathrm{m}$. $\boldsymbol{C}$, Here, the MF axon (black asterisk) gave rise to an end terminal located on a dendritic segment (de) in a P28 rat. Note the large pool of synaptic vesicles throughout the entire terminal and the mitochondria (white asterisks). The spiny excrescences (se) of the postsynaptic target dendrite were almost covered by the nerve terminal, and only here AZs at the postsynaptic apposition zone were observed. Scale bar, $1 \mu \mathrm{m}$. D, En passant MFB (P28) where the nerve terminal is invaginated by several axonal profiles (white asterisks) of unknown origin without establishing axoaxonic contacts. de, Postsynaptic dendrite; se, spiny excrescences. Scale bar, $1 \mu \mathrm{m}$. $\boldsymbol{E}$, Shape and distribution of PAs (marked by black asterisks) at the apposition zone of an MFB and its postsynaptic target dendrite (de) in a P28 rat. Note the dense row of mitochondria near the apposition zone. Scale bar, $0.25 \mu \mathrm{m}$. Inset, Individual PA at high magnification. Note the typical symmetric arrangement of the electron-dense material.

will lead to conditions in which unitary MF synaptic events trigger spikes in postsynaptic CA3 pyramidal neurons (Henze et al., 2002b; Lawrence et al., 2004). Because of these "conditional detonator" properties, MF activation may induce heterosynaptic LTP in CA3-CA3 pyramidal cell synapses (Kobayashi and Poo, 2004). Thus, the MF system may play a critical role in pattern completion, pattern separation, and storage of sequences of events (for review, see Bischofberger et al., 2006). Therefore, analysis of the structure of this synapse is essential to understand both synaptic transmission and the function of the hippocampal network.

To determine the structural factors underlying the unique function of the hippocampal MF system, the quantitative geometry was investigated, including several parameters relevant for transmitter release and synaptic plasticity. We demonstrate that several structural features of hippocampal MFBs differ fundamentally from the calyx of Held (Sätzler et al., 2002) and other previously investigated central presynaptic terminals (for review, see Rollenhagen and Lübke, 2006).

\section{Materials and Methods}

Fixation and tissue processing. All experiments were performed in accordance with the animal welfare guidelines of the University of Freiburg and the Institute of Neuroscience and Biophysics INB-3, Research Centre Jülich. For the reconstruction of individual MFBs and their postsynaptic target structures, the brains of seven young Wistar rats at postnatal day 28 (P28) and eight adult Wistar rats (3-4 months of age) were used. To look for intraindividual and interindividual differences, not only different animals but also different tissue blocks of the same animal were examined. The P28 rats were investigated to enable a direct correlation between the structural data in this paper and previous functional studies (Geiger and Jonas, 2000; Bischofberger et al., 2002; Hallermann et al., 2003; Engel and Jonas, 2005; Alle and Geiger, 2006).

The animals were deeply anesthetized with sodium pentobarbital (Nembutal; $60 \mathrm{mg} / \mathrm{kg}$ body weight) and then transcardially perfused with physiological saline followed by an icecold phosphate-buffered solution (PB) (100 mm solution, $\mathrm{pH} 7.4$ ) containing $4 \%$ paraformaldehyde and between 0.5 and $2.5 \%$ glutaraldehyde (Polyscience, Eppelheim, Germany) for $20-25 \mathrm{~min}$. After $1 \mathrm{~h}$ of postfixation, the brains were removed from the skull and stored overnight in fresh fixative at $4^{\circ} \mathrm{C}$. Serial $200-\mu \mathrm{m}$ thick vibratome sections (VT1000S; Leica Microsystems, Nussloch, Germany) were cut in the frontal plane through the hippocampus. Sections were then postfixed for $1 \mathrm{~h}$ in $100 \mathrm{~mm}$ PB-buffered 1\% osmium tetroxide, $\mathrm{pH} 7.4$, at room temperature in the dark. Thereafter, they were stained en bloc with an aqueous solution containing $1 \%$ uranyl acetate and $1 \%$ phosphotungstic acid (overnight), dehydrated in an ascending series of ethanol, followed by propylene oxide, and flat-embedded in Durcopan (Fluka, Neu-Ulm, Germany). Finally, sections were polymerized at $60^{\circ} \mathrm{C}$ for $2-3 \mathrm{~d}$.

Serial sectioning. Serial ultrathin sections $(55 \pm 5 \mathrm{~nm}$ in thickness; silver to light gray interference contrast appearance) were cut through the stratum lucidum of the CA3 subregion on a Leica Microsystems Ultracut $S$ ultramicrotome and collected on Formvar-coated slot copper 
Table 1. Quantitative analysis of structural elements of MFBs

\begin{tabular}{|c|c|c|c|c|c|c|c|c|c|c|c|c|}
\hline & \multicolumn{3}{|l|}{ Bouton } & \multicolumn{4}{|c|}{ Active zones } & \multicolumn{2}{|l|}{ Cleft width } & \multicolumn{3}{|c|}{ Excrescences } \\
\hline & $\begin{array}{l}\text { Volume } \\
\left(\mu \mathrm{m}^{3}\right)\end{array}$ & $\begin{array}{l}\text { Surface } \\
\left(\mu \mathrm{m}^{2}\right)\end{array}$ & $\begin{array}{l}\text { Contact area to } \\
\text { postsynaptic target } \\
{\left[\mu \mathrm{m}^{2}(\%)\right]}\end{array}$ & No. & $\begin{array}{l}\text { Mean } \\
\text { area } \pm S D\left(\mu m^{2}\right)\end{array}$ & $\begin{array}{l}\text { Total area } \\
{\left[\mu \mathrm{m}^{2}(\%)\right]}\end{array}$ & $\begin{array}{l}\text { Distance to } \\
\text { neighboring } \\
A Z \pm S D(\mu \mathrm{m})\end{array}$ & $\mathrm{AZ} \pm \mathrm{SD}(\mathrm{nm})$ & $P A \pm S D(n m)$ & No. & $\begin{array}{l}\text { Total area } \\
\left(\mu \mathrm{m}^{2}\right)\end{array}$ & $\begin{array}{l}\text { PSD area } \\
{\left[\mu \mathrm{m}^{2}(\%)\right]}\end{array}$ \\
\hline \multicolumn{13}{|l|}{ P28 } \\
\hline 1 & 6.02 & 42.00 & $21.14(50.3)$ & 19 & $0.11 \pm 0.06$ & $2.05(9.7)$ & $0.44 \pm 0.24$ & $30.29 \pm 4.10$ & $27.68 \pm 2.56$ & 2 & 13.00 & 1.77 (13.6) \\
\hline 2 & 8.16 & 105.70 & $41.22(39.0)$ & 37 & $0.09 \pm 0.04$ & $3.40(8.2)$ & $0.42 \pm 0.27$ & $31.90 \pm 5.13$ & $29.12 \pm 1.45$ & 7 & 30.00 & $2.85(9.5)$ \\
\hline 3 & 5.05 & 48.40 & $20.68(42.7)$ & 18 & $0.13 \pm 0.10$ & 2.39 (11.6) & $0.42 \pm 0.15$ & $30.93 \pm 2.82$ & $19.78 \pm 2.10$ & 5 & 14.90 & $2.36(15.8)$ \\
\hline 4 & 9.15 & 106.00 & $48.33(45.6)$ & 45 & $0.12 \pm 0.08$ & 5.49 (11.4) & $0.33 \pm 0.16$ & $30.69 \pm 5.27$ & $25.63 \pm 2.64$ & 9 & 35.90 & $5.07(14.1)$ \\
\hline Mean & 7.10 & 75.53 & 32.84 (44.4) & 29.75 & $0.12 \pm 0.10$ & $3.33(10.2)$ & $0.40 \pm 0.20$ & $30.95 \pm 1.13$ & $25.55 \pm 0.55$ & & 23.45 & $3.01(13.3)$ \\
\hline CV & 0.27 & 0.46 & $0.43(0.1)$ & & 0.83 & $0.46(0.20)$ & 0.49 & 0.04 & 0.02 & & 0.48 & $0.48(0.20)$ \\
\hline \multicolumn{13}{|l|}{ Adult } \\
\hline 1 & 13.03 & 82.19 & $31.56(38.4)$ & 34 & $0.07 \pm 0.05$ & $2.26(7.2)$ & $0.32 \pm 0.09$ & $28.11 \pm 3.26$ & $19.62 \pm 2.63$ & 4 & 20.90 & $2.12(10.1)$ \\
\hline 3 & 5.42 & 50.55 & $21.00(41.9)$ & 14 & $0.14 \pm 0.13$ & $2.01(9.5)$ & $0.52 \pm 0.14$ & $29.46 \pm 5.22$ & $20.25 \pm 2.58$ & 5 & 14.00 & $1.24(8.8)$ \\
\hline 4 & 12.17 & 68.90 & $24.13(35.0)$ & 18 & $0.17 \pm 0.10$ & $3.06(12.7)$ & $0.60 \pm 0.27$ & $19.74 \pm 0.65$ & $20.66 \pm 3.20$ & 7 & 20.00 & $2.68(13.4)$ \\
\hline 7 & 2.35 & 32.37 & $11.39(35.2)$ & 7 & $0.15 \pm 0.08$ & $1.07(9.4)$ & $0.47 \pm 0.27$ & $29.81 \pm 3.09$ & $20.48 \pm 0.44$ & 3 & 9.22 & $0.91(9.9)$ \\
\hline Mean & 8.24 & 58.50 & $22.07(37.6)$ & 18.25 & $0.11 \pm 0.07$ & $2.10(9.7)$ & $0.48 \pm 0.19$ & $26.78 \pm 1.87$ & $20.25 \pm 1.21$ & & 16.03 & 1.74 (10.6) \\
\hline $\mathrm{CV}$ & 0.63 & 0.37 & $0.38(0.1)$ & & 0.64 & $0.39(0.20)$ & 0.40 & 0.07 & 0.06 & & 0.34 & $0.47(0.20)$ \\
\hline
\end{tabular}

Summary of structural parameters relevant for synaptic transmission that have been extracted from the detailed 3-D reconstructions of MFBs in P28 and adult rats. The quantifications of two additional very small boutons (surface area of 8.2 and $13.9 \mu \mathrm{m}^{2}$; contact area to postsynaptic target of 4.5 and $2.3 \mu \mathrm{m}^{2}$; and a pool size of 2533 and 2795 , respectively) were not included because they may resemble satellites (Galimberti et al., 2006 ) or belong to filopodia. The values of the cleft width of AZs and PAs were taken from measurements at the center of both membrane specializations (see also text). The means and CVs given in this table are averages per bouton.

or nickel grids. Because the cross diameter of MF boutons ranged from 2 to $5 \mu \mathrm{m}$, a full series comprised 50-150 ultrathin sections. For both ages, serial ultrathin sections were taken from different animals to check for interindividual differences. Four MFBs from P28 and six MFBs from adult rats were reconstructed and analyzed completely. Individual MFBs were judged to be complete by the following criteria: the main body can be unequivocally identified from the beginning to its end in a series of ultrathin sections, and fine structures such as filopodia can be followed from their place of origin at the main body to their end.

In addition, three P28 and two adult MFBs were partially reconstructed and analyzed in certain aspects, such as surface and volume of spiny excrescences, active zones (AZs), puncta adherentia (PAs), and synaptic vesicles.

Distinction between AZs and PAs. To unequivocally distinguish between the two membrane specializations, AZs and PAs, found at the apposition zone between the MFBs and their postsynaptic targets, the following three criteria were applied: (1) the presence of synaptic vesicles in close proximity to the presynaptic density, (2) an asymmetry between the presynaptic and postsynaptic density, and (3) a characteristic widening of the synaptic cleft. For the complete reconstructions, all membrane specializations that met the three criteria were classified as AZs. All other membrane specializations were categorized as PAs.

To quantitatively validate criterion 3 , the cleft width of both AZs (P28 and adult, $n=25$ each) and PAs (P28 and adult, $n=25$ each) was measured in the center and at two edges (at the appearance and disappearance of the presynaptic and postsynaptic densities) of the two membrane specializations. Measurements were directly performed at individual images taken from the series of ultrathin sections of single boutons at both P28 and adult animals (see Table 1). The measurements for the two edges were pooled and compared with the values taken at the center. Only AZs and PAs that were perpendicularly cut and that showed a clearly visible cleft were included in the sample.

Three-dimensional reconstructions. Individual MFBs were photo-

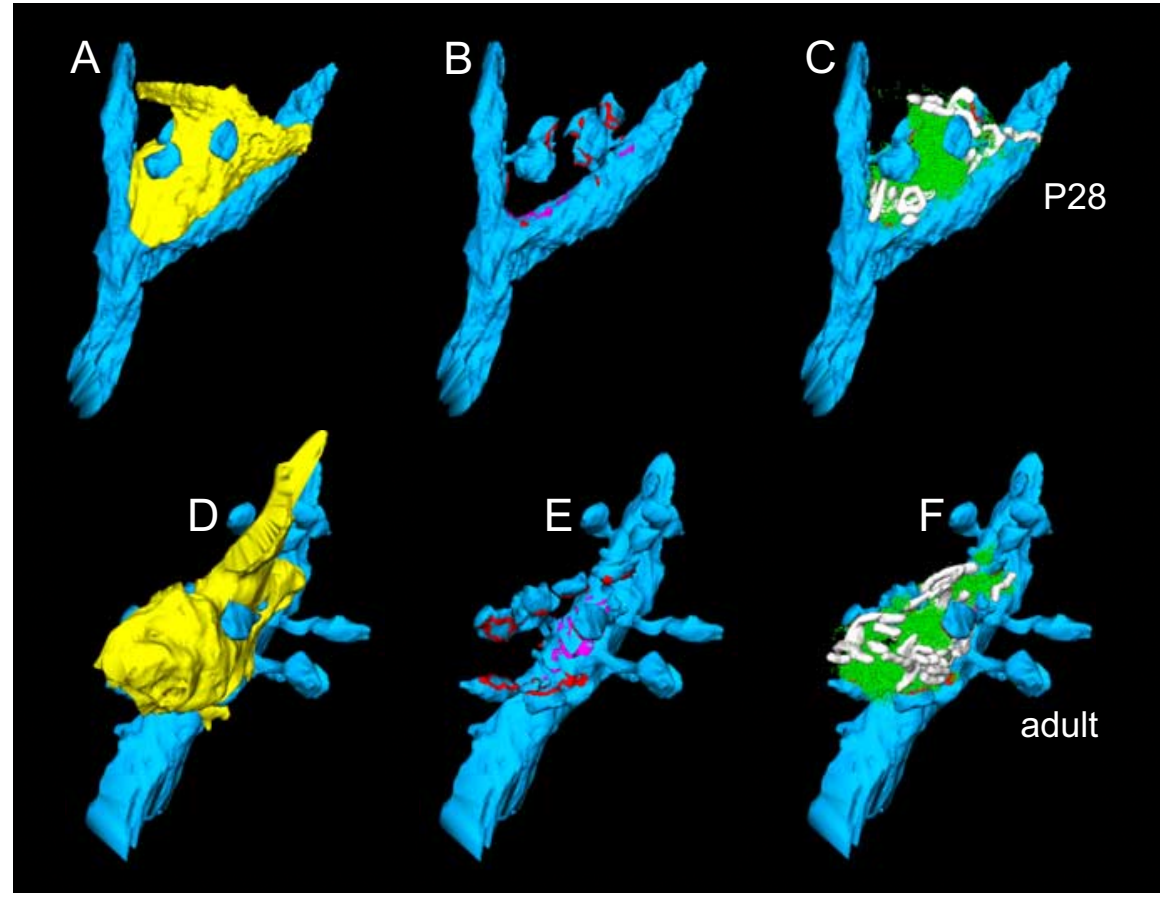

Figure 2. Three-dimensional reconstructions of the MFBs and their postsynaptic target dendrite. $A, D$, Volume reconstructions of two en passant MF boutons (depicted in yellow) and their postsynaptic target dendrite (blue) from a P28 ( $\boldsymbol{A}$ ) and an adult rat (D). Note that the spiny excrescences were almost entirely covered by the nerve terminal. $\boldsymbol{B}, \boldsymbol{E}$, Distribution of the two membrane specializations, AZs (red) and PAs (magenta), on the postsynaptic target dendrite (blue). AZs were located on the spiny excrescences, whereas PAs were exclusively found at the dendritic shaft. $C, F$, Organization of the pool of synaptic vesicles (green dots) at the two MFBs. In both cases, the pool was distributed throughout the entire nerve terminal. Mitochondria (white) formed either cluster-like arrangements or bands associated with the pool of synaptic vesicles.

graphed from the series of ultrathin sections at a primary magnification of 5.900× (Zeiss EM 10; Zeiss, Oberkochen, Germany) and 9.800× (Philips 100; Philips, Eindhoven, Netherlands), respectively. The negatives were scanned and stored as TIF or JPEG images with a resolution of $1.300 \mathrm{dpi}$ or $2.000 \mathrm{dpi}$, resulting in a pixel size of $1.2-2 \mathrm{~nm}$. The electron microscopic images were imported into the reconstruction software CAR (Contour Alignment Reconstruction; software developed by K. Sätzler), stacked, and transformed linearly such that corresponding structures were aligned along all consecutive images comprising the threedimensional (3-D) image stack (for details, see Sätzler et al., 2002). 


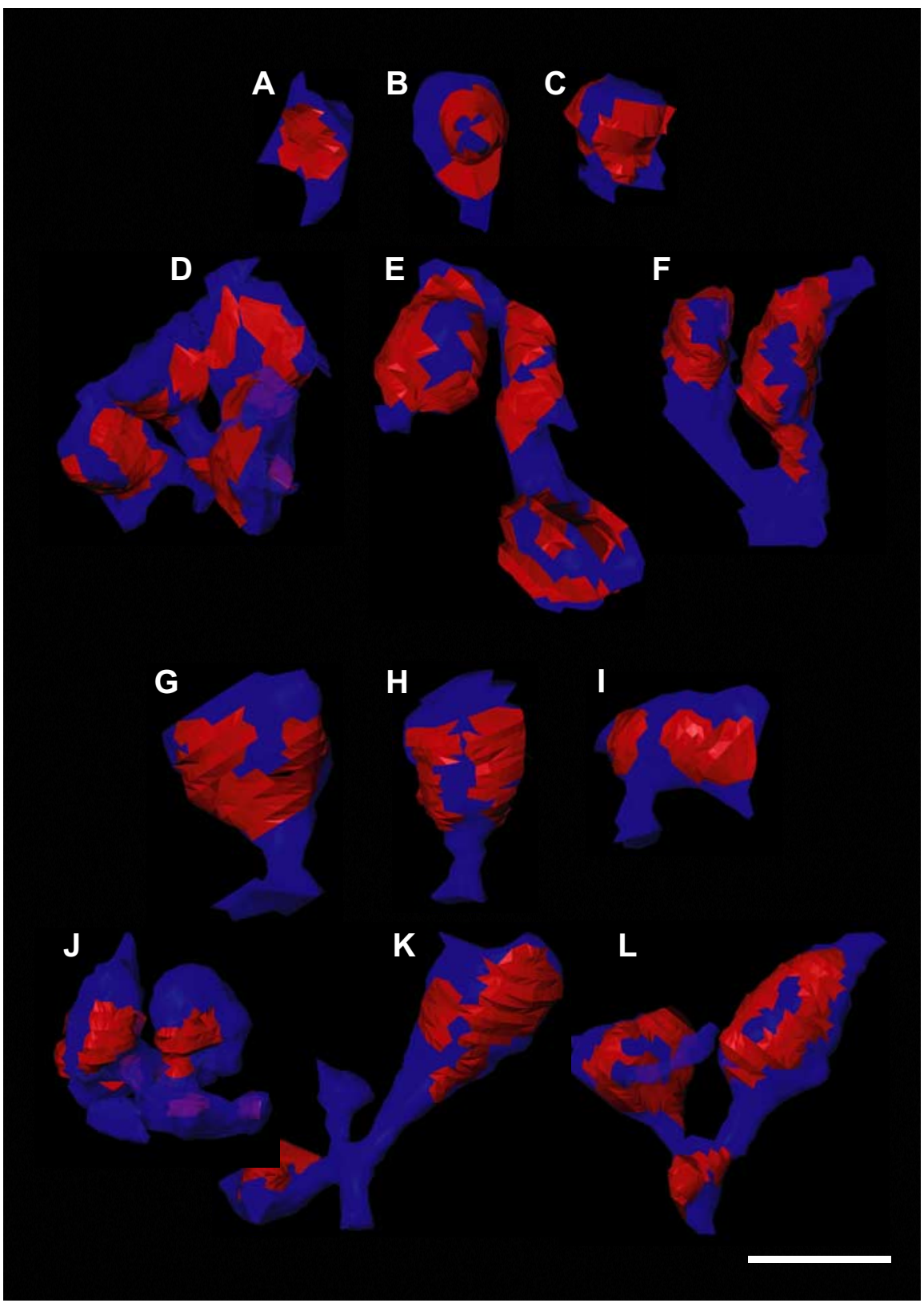

Figure 3. Number, shape, and location of AZs. Representative examples of AZs (red areas) found on simple and complex spiny excrescences (blue) taken from different P28 $(\boldsymbol{A}-\boldsymbol{F})$ and adult $(\boldsymbol{G}-\boldsymbol{L})$ rats. All spines are shown at the same scale. The surface of the spine was made transparent to visualize AZs located on the opposite side of the spine. Simple spines had only a single $(A, B, G)$ or at most two AZs $(C, H, L)$, whereas complex spines had up to eight AZs $(D)$. Note also the different shape and size of individual AZs that formed ring-like structures $(\boldsymbol{E}, \boldsymbol{F}, \boldsymbol{L})$, or patch-like $(\boldsymbol{A}, \boldsymbol{C}, \boldsymbol{I}, \boldsymbol{J})$ or band-like arrangements $(\boldsymbol{D}, \boldsymbol{E}, \boldsymbol{F}, \boldsymbol{H})$. Scale bar, $1 \mu \mathrm{m}$.

Ineach image series comprising a 3-D stack (six times 3-D stacks were analyzed with a total number of 647 micrographs), all presynaptic structures of interest such as the MFB and its mitochondria as well as postsynaptic structures like dendritic shafts and spiny excrescences were marked using closed contour lines in CAR. From these polygonal cross sections, 3-D volumetric reconstructions were performed from which surface and volume measurements were obtained. Additional surface estimates for AZs and PAs were computed by extracting those areas from the reconstructed presynaptic and postsynaptic membranes that were covered by the membrane specializations. All calculations were performed off-line using a batch version of CAR, which generates 3-D reconstructions as well as space-delimited tables for each measurement which are readable by standard analysis software. For additional details on 3-D reconstructions, see Sätzler et al. (2002).

Tissue shrinkage may affect the reported morphological parameters.
Shrinkage factors critically depend on the fixative used, the subsequent tissue processing, and the embedding media for electron microscopy. Furthermore, shrinkage factors may not be identical for different subcellular elements. Therefore, it is difficult to estimate a universal shrinkage factor. Finally, shrinkage may also affect the location of mobile elements, such as synaptic vesicles with respect to the AZ. The extent of these effects will have to be determined by detailed comparison of different fixation and embedding techniques, including high-pressure freezing (Rostaing et al., 2006). Based on these uncertainties, the results presented here remained uncorrected for shrinkage.

Estimating vesicle distribution and pool sizes. To obtain estimates for synaptic vesicle size and distance distribution, we marked each vesicle in a bouton and measured its diameter and the minimal distance between its center of gravity and the closest presynaptic density of an AZ. This distance diminished by one vesicle radius gives an estimate of the minimal twodimensional (2-D) distance that a vesicle had to bridge before it "touches" the membrane specialization. Because the minimal 2-D distance for each vesicle to either an AZ or PA was measured, it was possible to define different pools of synaptic vesicles for each $\mathrm{AZ}$ depending on the vesicle perimeter and plot their distribution (see Fig. 8, Table 2).

Several potential errors in vesicle counting were considered. First, vesicle counting might be subjective in ultrathin sections with suboptimal quality. To address this issue, six micrographs of relatively low image quality were selected and vesicles were traced by different experimenters involved in this project. We then compared final counts, diameter, and distance estimates and calculated the mean and SD, which gave an upper bound for this source of variability. The variability for the mean diameters and distances reported was $\pm 5.5 \mathrm{~nm}$ [coefficient of variation (CV), 0.18$]$ and $\pm 4.2 \mathrm{~nm}$ $(\mathrm{CV}, 0.01)$, respectively. Second, errors in estimates of vesicle numbers may occur by double counts of individual vesicles in adjacent sections (Abercrombie, 1946). To address the possibility of double counts of small clear vesicles, we simulated the appearance of these vesicles in ultrathin sections under conditions when the vesicle diameter was comparable with the thickness of the sections $(\sim 50 \mathrm{~nm})$ (A. Roth and $\mathrm{K}$. Sätzler, unpublished data). These simulations revealed that synaptic vesicles showed a clear ring-like appearance in electron micrographs only if $\geq 50 \%$ of their volume was present in an ultrathin section. Because only clear ring-like structures were counted as vesicles, double counts were highly unlikely under these circumstances. Additionally, it is possible that vesicles are missed in densely packed regions, because ring-like traces partly overlap. This effect may counteract any double counts. Based on the small extent and the partially counteracting nature of the effects, the numbers of small clear vesicles reported in this study remained uncorrected. For large dense-core vesicles, double counts were excluded by careful examination of adjacent images and were only counted in the image where they appeared largest.

Statistical analysis. From the numerous 3-D reconstructions and spreadsheets computed by CAR, statistical summaries and graphs were generated automatically using special purpose functions written for the 
freely available statistics package $\mathrm{R}$ ( $\mathrm{R}$ Development Core Team, 2005) (http://www.Rproject.org). To assess differences in the distributions of various measurements, in particular the pool sizes of synaptic vesicles, the nonparametric Kolmogorov-Smirnov test was used. For assessing differences in the mean of approximately normally distributed measurements like vesicle diameters and cleft widths, the twotailed Student's $t$ test was used. Results were considered significant if $p<0.05$. Where appropriate, $p$ values were explicitly specified.

Glutamine synthetase preembedding immunohistochemistry. To examine the topography of the glial coverage at the MFB-CA3 pyramidal cell synapse (Derouiche and Frotscher, 1991), two P28 and two adult rats were transcardially perfused with $100 \mathrm{~mm}$ PB-buffered $4 \%$ paraformaldehyde and $0.5 \%$ glutaraldehyde. After postfixation, $100 \mu \mathrm{m}$ vibratome sections were cut in the frontal plane. The hippocampus was dissected from the sections and then cryoprotected in $100 \mathrm{~mm}$ 10\% PB-buffered (30 min) and $20 \%$ sucrose overnight. Sections were then freeze-thawed in liquid nitrogen, rinsed in 100 $\mathrm{mm}$ PB, blocked in $100 \mathrm{~mm}$ PBS containing $0.5 \%$ goat serum albumin $(1.5 \mathrm{~h})$, and finally incubated in monoclonal mouse antiglutamine synthetase antibody (1:1000; Chemicon, Hampshire, UK) overnight at $4^{\circ} \mathrm{C}$. After several rinses in $100 \mathrm{~mm}$ PBS, sections were incubated in biotinylated anti-mouse secondary antibody for $2 \mathrm{~h}$ (1:100; Vector; Linaris, Wertheim, Germany). This was followed after several washing steps in $100 \mathrm{~mm}$ PBS by incubation in $100 \mathrm{~mm}$ PBS-buffered ABC-Elite solution for $2 \mathrm{~h}$ (1:100; Vector; Linaris). Sections were then reacted in $50 \mathrm{~mm}$ Tris-buffered $3,3^{\prime}$ diaminobenzidine for $10 \mathrm{~min}$. After several rinses in $100 \mathrm{~mm}$ PBS, they were postfixed in $100 \mathrm{~mm}$ sucrose-PBS-buffered $0.5 \%$ osmium tetroxide (30 $\mathrm{min}$ ), dehydrated through an ascending series of ethanol, propylene oxide, and finally flat-embedded in Durcopan (Fluka). After polymerization (at $60^{\circ} \mathrm{C}$ for $2-3 \mathrm{~d}$ ), sections containing immunoreactive astrocytic profiles in the stratum lucidum were selected and serial ultrathin sections were taken at $\sim 55 \mathrm{~nm}$ thickness. After counterstaining with uranylacetate and lead citrate, they were examined and photographed with a Zeiss Libra 120 electron microscope using the SIS Analysis software (Soft Imaging System, Münster, Germany). The ultrathin sections provided the basis for the serial reconstructions of astrocytic processes around individual MFBs as described above.

\section{Results}

\section{General description of the structure of the MFB}

The axons of granule cells in the dentate gyrus constitute a massive fiber bundle, the MFs that establish large, highly specialized en passant boutons (Fig. 1 $A, D$; supplemental movie, available at www.jneurosci.org as supplemental material) or end terminals (Fig. 1C) with proximal dendritic segments predominantly on spiny (thorny) excrescences (Figs. $1 A, C, 6 A-D, F, G$ ) of excitatory CA3 pyramidal cells. These dendrites receive dense synaptic input from multiple MFBs (Fig. 1B); in turn, individual MFBs contact several dendritic segments of the same (Chicurel and Harris, 1992) or different pyramidal neurons (Galimberti et al., 2006). In both P28 and adult rats (between 3 and 4 months of age), the density of MFBs in the stratum lucidum was remarkably high. At the dendritic segment shown in Figure $1 B$, which is $\sim 10$ $\mu \mathrm{m}$ in length, $10 \mathrm{MFBs}$ of variable shape and size were found.

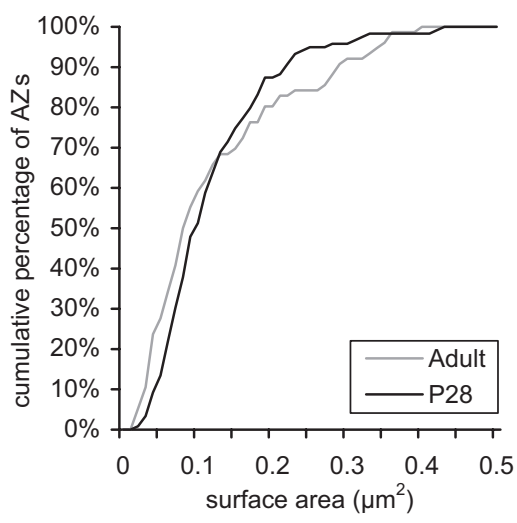

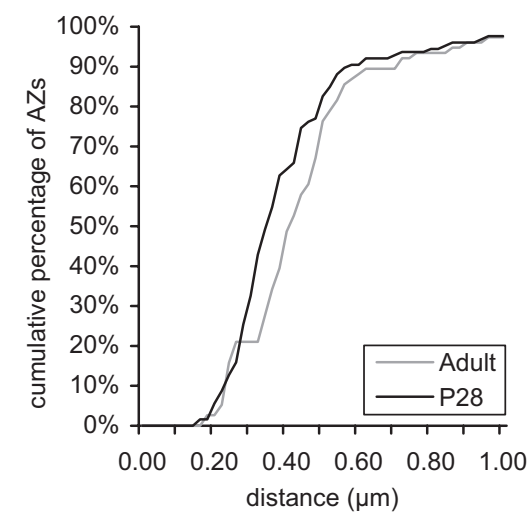

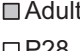

P28
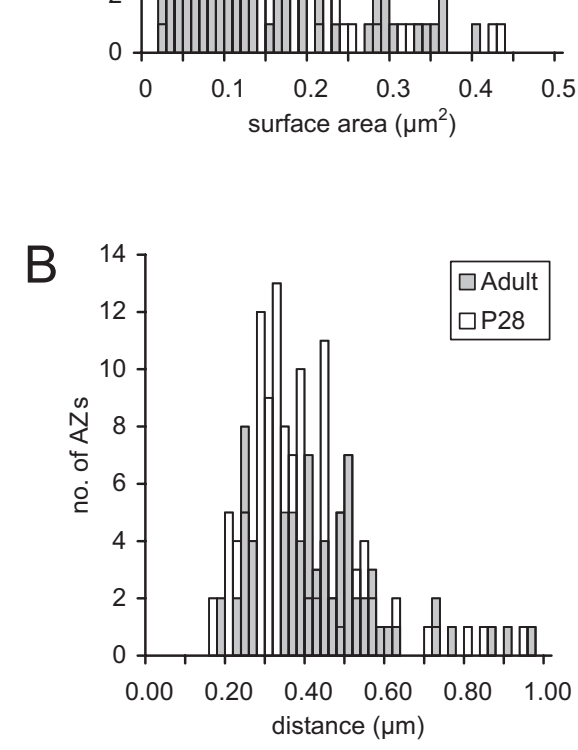

Figure 4. Area and distance distribution of AZs. A, Histogram (left) of the distribution of surface areas of all AZs for P28 (black hollow bars) and adult (gray solid bars) MFBs and their corresponding cumulative histogram (right). Bin width is $0.01 \mu \mathrm{m}^{2}$. The ight panel shows the corresponding cumulative histogram (same color code). Bin width is $0.02 \mu \mathrm{m}$. The two distributions are significantly different ( $p \leq 0.05$, Kolmogorov-Smirnov test).

In both $\mathrm{P} 28$ and adult rats, MFBs were highly variable in shape and size (Figs. $1 A-D, 6 A-D$ ) ranging from 2 to $5 \mu \mathrm{m}$ in cross diameter, from 40 to $110 \mu \mathrm{m}^{2}$ in surface area, and from 2 to 13 $\mu \mathrm{m}^{3}$ in volume (Table 1 ). In addition, small caliber boutons ranging from 8.2 and $13.9 \mu \mathrm{m}^{2}$ in surface area and with a volume of $<1 \mu \mathrm{m}^{3}$ were observed (Fig. $1 \mathrm{~B}, \mathrm{MFB} 1$ ). However, these small boutons may either resemble those described as satellites (Galimberti et al., 2006) or could emerge from filopodia (Acsády et al., 1998) (Table 1). On average, two to four filopodial extensions of various shapes and lengths $(1-5 \mu \mathrm{m})$ emerged from the main body of the nerve terminal, sometimes terminating abruptly or in an endbulb-like structure (supplemental movie, available at www.jneurosci.org as supplemental material). In our sample, these endbulbs often contained a single AZ.

The larger MFBs contained numerous mitochondria of various size (P28, 21-42; adult, 33-57) that either formed cluster-like arrangements (Figs. $1 A, C, 2 C, F$; supplemental movie, available at www.jneurosci.org as supplemental material) or constituted row-like assemblies (Fig. 1C,E). Mitochondria contributed between 4 and $12 \%$ to the total volume of individual boutons. Mitochondria not only act as internal calcium stores (Rizzuto et al., 2000) but may also regulate internal $\mathrm{Ca}^{2+}$ levels in the terminal. Furthermore, mitochondria may be involved in the mobilization of synaptic vesicles from the reserve pool (Verstreken et al., 2005). In MFBs, mitochondria were seen to be associated with the pool of synaptic 

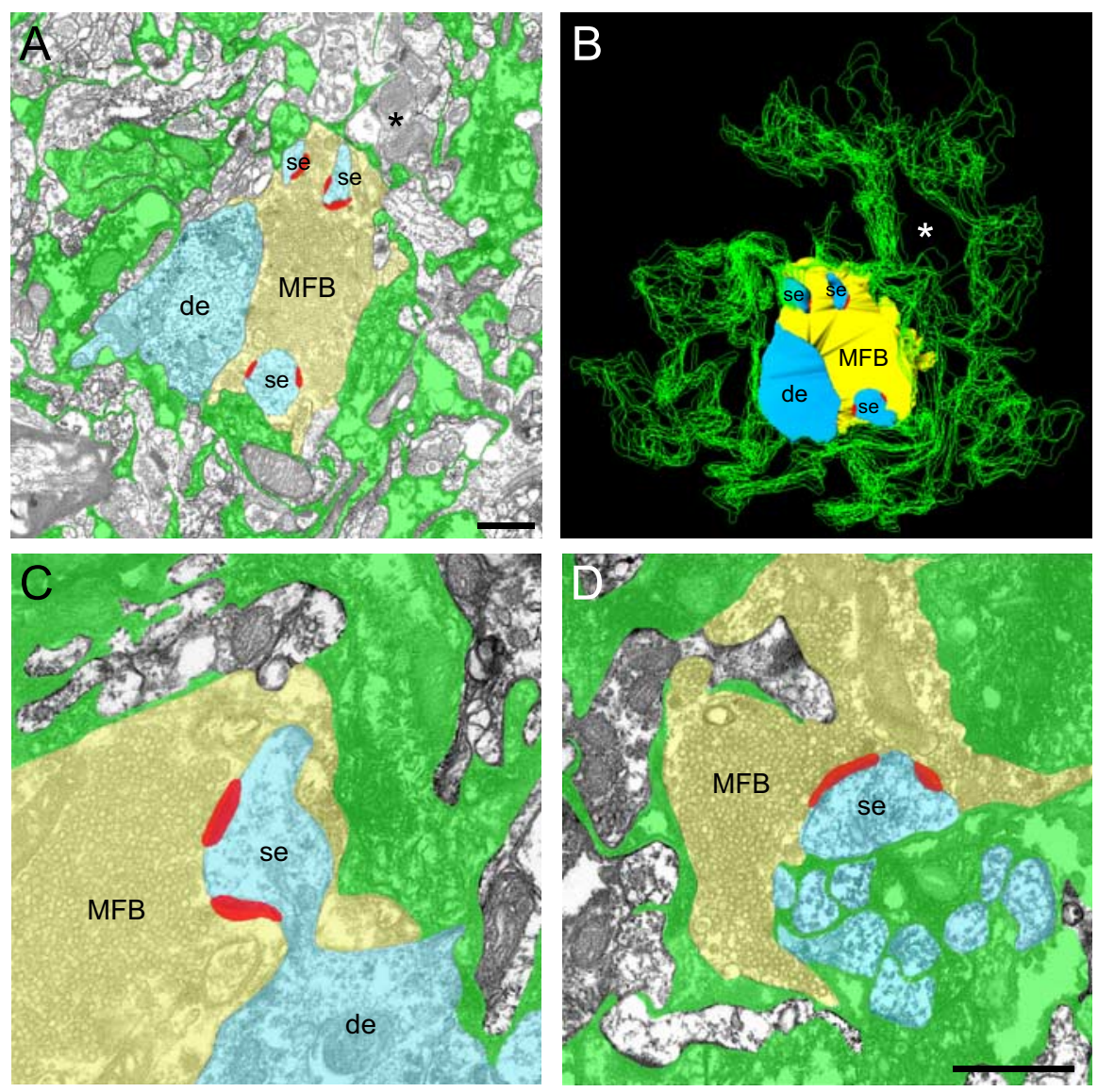

Figure 5. Glial coverage of individual MFBs. A, Low-power electron micrograph showing the distribution of astrocytic processes (highlighted in green) as revealed by glutamine synthetase preembedding immunohistochemistry. The surface of an individual MFB (in light yellow), its postsynaptic target dendrite (de), and its spiny excrescences (se) (in light blue) was surrounded by several astrocytic processes. The black asterisk indicates another MFB that was clearly separated from the MFB given in light yellow. Scale bar, $1 \mu \mathrm{m}$. $B$, Three-dimensional reconstruction showing the astrocytic processes that surround the complex of the MFB, the postsynaptic dendrite, and the spiny excrescences shown in $A$. Note that the fine astrocytic fingers covered the presynaptic and postsynaptic apposition zone of the synaptic complex, but did not reach as far as the AZs (red) located on the spiny excrescences. The white asterisk indicates the location of another adjacent MFB and its postsynaptic target, which were not reconstructed. C, D, Two high-power electron micrographs showing the distribution of astrocytic processes (highlighted in green). The surface of the two individual MFBs (in light yellow), their postsynaptic target dendrite (de), and the spiny excrescences (se) (in light blue) were surrounded by several astrocytic processes. Note that fine astrocytic processes were never seen at the spiny excrescences and never reached as far as the active zones (highlighted in red). Scale bar: $C, D, 0.5 \mu \mathrm{m}$.

vesicles (Figs. $1 A, C, 2,6 A-D)$. However, they were not organized in mitochondria-associated complexes (Rowland et al., 2000) or donut-like assemblies (Wimmer et al., 2006) as described for the calyx of Held nerve terminal. Interestingly, most of the MFBs investigated were penetrated and crossed by other axons of different caliber and of undefined origin (Fig. $1 D$ ), a phenomenon that has not been reported yet for the MFB and other large central synapses. However, these axons never established axoaxonic contacts with the MFBs.

As described for other large central synapses, two membrane specializations were found at the presynaptic and postsynaptic apposition zone: AZ, the sites of transmitter release, and puncta adherentia (PA), which are thought to function as adhesion complexes.

\section{Membrane specializations at the presynaptic and postsynaptic apposition zone}

$A Z s$

By definition, an AZ is characterized by the dense accumulation of synaptic vesicles located in close proximity to the presynaptic density, the asymmetric presynaptic and postsynaptic densities, and the characteristic widening of the synaptic cleft (see Fig. $6 E-G)$. The presynaptic and postsynaptic densities formed bands of electron-dense fuzzy material. At individual MFBs, two types of AZs were found: the majority $(\sim 80 \%)$ had presynaptic and postsynaptic densities that were frequently interrupted, appearing as perforated structures (see Fig. $6 E$ ), whereas the remaining AZs showed perforations in either the presynaptic or postsynaptic densities (see Fig. $6 F$ ) or were nonperforated. The average cleft width, measured under the presynaptic and postsynaptic densities was $30.95 \pm 1.13$ $\mathrm{nm}$ and $20.52 \pm 3.08$ at the edges (P28). In adults rats, the cleft width was $26.78 \pm$ $1.87 \mathrm{~nm}$ in the center and $17.59 \pm 2.93$ at the edges (Table 1). The difference in the means between center and the edges of AZs was significantly different $(p \leq 0.001)$ in both P28 and adult rats. Interestingly, the cleft widths of AZs was also significantly different $(p \leq 0.05)$ between both age groups (Table 1 ).

The distribution of $\mathrm{AZs}$ and PAs is illustrated in Figure 2, $B$ and E; AZs are depicted in red and PAs in magenta. In both ages, AZs were located on the spiny excrescences, whereas PAs were exclusively found on dendritic shafts (supplemental movie, available at www.jneurosci.org as supplemental material). Two types of spiny excrescences could be distinguished on the postsynaptic target dendrites: the so-called simple spines were contacted only by a single, but often very large, AZ (Fig. $3 A, B, G$ ) or at most two AZs (Fig. 3C, $H, I$ ). In contrast, complex spines were contacted by up to eight AZs that were predominantly located opposite to spine heads (Fig. $3 D-F, J-L$ ). The AZs varied substantially in shape and size, forming patches (Fig. $3 A, C, I, J$ ), bands (Fig. $3 D-F$ ), or ring-like structures (Fig. 3 B,E, F,L), and covered on average 13.3\% (P28) or $10.6 \%$ (adult) of the total surface area of the spiny excrescences (Table 1).

Number and size of $A Z s$

The mean number of AZs was 29.80 (range, 18-45) in MFBs from P28 and 18.30 (7-34) in adult rats (Table 1). Individual AZs varied substantially in shape and size; both very large $\left(0.17 \mu \mathrm{m}^{2}\right)$ and very small $\left(0.07 \mu \mathrm{m}^{2}\right)$ AZs were found. The mean surface area of AZs was $0.12 \pm 0.10 \mu \mathrm{m}^{2}$ in P28 and $0.11 \pm 0.07 \mu \mathrm{m}^{2}$ in adult rats. In both ages, the distribution in size was characterized by a large variability as indicated by the CV ranging between 0.83 (P28) and 0.64 (adult), respectively (Fig. 4A, Table 1). No significant difference in surface area was found between both ages $(p>$ $0.1)$.

Distance between individual AZs

Another critical structural determinant for synaptic transmission is the spacing (nearest-neighbor distance) between individual 

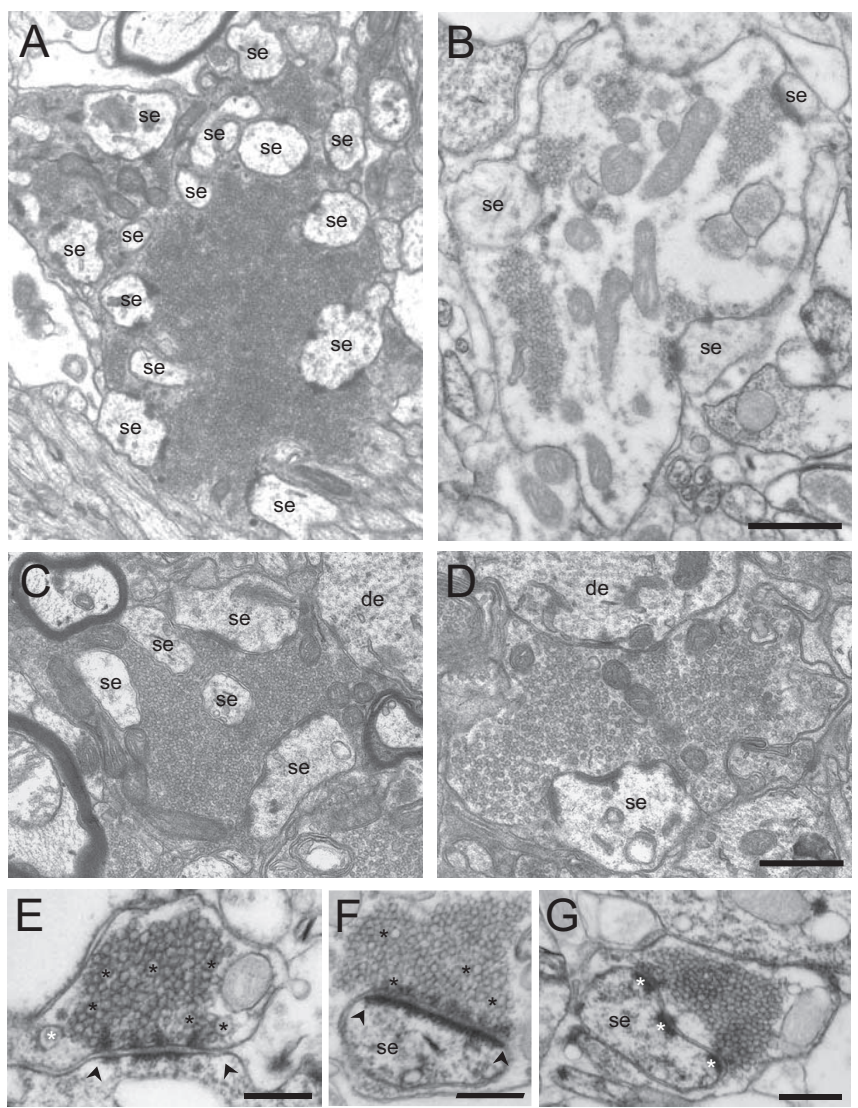

Figure 6. Organization of the pool of synaptic vesicles. $\boldsymbol{A}$, Representative example of the organization of the pool of synaptic vesicles within a MFB of a P28 rat. Here, the synaptic vesicles were distributed throughout the entire terminal. No cluster-like arrangement of individual pools of synaptic vesicles around AZs at spiny excrescences (se) was observed. $\boldsymbol{B}$, Distribution of individual pools of synaptic vesicles in a MFB of an adult rat. In contrast to the bouton shown in $A$, cluster-like arrangements of individual pools of synaptic vesicles at AZs at spiny excrescences (se) were clearly visible. Scale bar: $A, B, 0.5 \mu \mathrm{m}$. C, D, Organization of synaptic vesicle pools in MFBs taken from two different $P 28$ rats. Although both MFBs were of comparable size, the pool of synaptic vesicles in $\boldsymbol{C}$ seems to be larger and more condensed than that in $\boldsymbol{D}$. de, Postsynaptic dendrite; se, spiny excrescences. Scale bar: $C, D, 0.5 \mu \mathrm{m}$. $E$, AZ with a perforated presynaptic and postsynaptic density. Here, the characteristic widening of the synaptic cleft (between the arrowheads) is clearly visible. Note the large clear vesicles (black asterisks) and a single dense-core vesicle (white asterisk). $\boldsymbol{F}$, AZ with a nonperforated postsynaptic density (arrowheads) on a spine-like excrescence (se). Within the pool of synaptic vesicles, several large clear vesicles (black asterisks) were observed. At the presynaptic density also, several docked vesicles can be identified. G, Row of three AZs (white asterisks) located at an individual spiny excrescence (se). Here, the pool of synaptic vesicles is shared by all three AZs. Scale bar: $\boldsymbol{E}-\mathbf{G}, 0.25 \mu \mathrm{m}$.

AZs. Release sites that are close to each other suggest that glutamate spillover and as a consequence synaptic cross talk may occur at these synapses (Barbour and Häusser, 1997). The average distance between AZs was measured as Euclidian distance in 3-D space between the centers of gravity of neighboring AZs at the same or different spiny excrescences. For P28, the average distance was $0.40 \pm 0.20 \mu \mathrm{m}, 0.48 \pm 0.19 \mu \mathrm{m}$ in adult, and was not significantly different between both ages. However, the nearestneighbor distances varied widely $(0.20-0.60 \mu \mathrm{m})$, as also indicated by the large SD and CV (Fig. $4 B$, Table 1).

$P A s$

The second type of membrane specializations were PAs (Fig. 1E) (Hamlyn, 1962; Honda et al., 2006). These were characterized by two parallel bands of electron-dense material of approximately the same width at the presynaptic and postsynaptic membranes, but lacking synaptic vesicles and the characteristic broadening of the cleft typical for AZs (compare Figs. $1 E$, inset, $6 E, F$ ). For PAs, the average cleft width was $25.55 \pm 0.55 \mathrm{~nm}$ in the center and $22.85 \pm 4.81 \mathrm{~nm}$ at the edges of the two densities in P28 rats and $20.25 \pm 1.21 \mathrm{~nm}$ in the center and $19.93 \pm 0.97$ at the edges of the two densities in adult rats (Table 1). In contrast to AZs, the difference in the means between the center and the edges at the two densities was not significantly different at P28 $(p>0.1)$ and adult rats $(p>0.3)$. Interestingly, as for AZs, the cleft width of PAs was significantly different ( $p \leq 0.05$ ) between both age groups (Table 1). Our analysis of PAs is in good agreement with quantitative data reported previously (Hamlyn, 1962).

At individual MFBs, the majority of PAs were organized in rows of up to 15 PAs that were exclusively found at the apposition zone of the presynaptic terminal and the dendritic shaft (Figs. $1 E$, $2 B, E$; supplemental movie, available at www.jneurosci.org as supplemental material). Their numbers ranged between 12 and 24 in P28 and between 2 and 13 in adult rats. The surface area of individual PAs was, on average, $0.07 \mu \mathrm{m}^{2}$, approximately onehalf of the size of individual AZs. Their size distribution showed a similar degree of variability $(\mathrm{CV}, 0.8)$.

Both membrane specializations were spatially separated from each other; PAs were exclusively found at the apposition zone between the bouton and the dendritic shaft, whereas AZs were located on the spiny excrescences (Fig. $2 B, E$ ). This segregation is in marked contrast to the calyx of Held (Sätzler et al., 2002) (see Discussion).

\section{Glial coverage of MFBs}

Glial cells, in particular astrocytes and their fine processes, play an important role in synaptic function, acting as physical barriers to glutamate diffusion and mediating transmitter uptake by glutamate transporters. Preembedding immunohistochemistry against glutamine synthetase, a key enzyme in astrocytes, was performed to examine the structural relationship between individual MFBs and astrocytes. Three MFBs, their postsynaptic dendrites, and the astrocytic processes were three-dimensionally reconstructed. A large fraction of the surface area of individual boutons was surrounded by astrocytic processes (Fig. $5 A$ ). Thus, the synaptic complex consisting of an MFB and its postsynaptic target dendrite was physically isolated not only from the surrounding neuropil but also from neighboring synaptic complexes (Figs. $1 B, 5 B$ ). In contrast to other synapses (for review, see Rollenhagen and Lübke, 2006), glial fingers were never observed to reach as far as to individual AZs located at the spiny excrescences or even the synaptic cleft (Fig. 5C,D); instead spiny excrescences were almost completely covered by the boutons (Fig. 2A, D; supplemental movie, available at www.jneurosci.org as supplemental material).

\section{Organization of the pool of synaptic vesicles}

Another key determinant for synaptic efficacy and plasticity is the organization of the pool of synaptic vesicles, in particular, the size of the RRP, the RP, and the reserve pool as measured by imaging, capacitance measurements, and quantal analysis studies (Schneggenburger et al., 1999; Sahara and Takahashi, 2001; Sun and Wu, 2001; Hallermann et al., 2003; Saviane and Silver, 2006) (for review, see Schneggenburger et al., 2002; Rizzoli and Betz, 2004, 2005).

Synaptic vesicles in individual MFBs were distributed throughout the entire terminal (Figs. $1 A, C, D, 6 A-D$ ) and comprised an average volume of $0.49 \mu \mathrm{m}^{3}$ for P28 and $0.26 \mu \mathrm{m}^{3}$ in adult rats, corresponding to 6.4 and $4.2 \%$ of the total volume of the boutons. However, we found a marked difference in the or- 


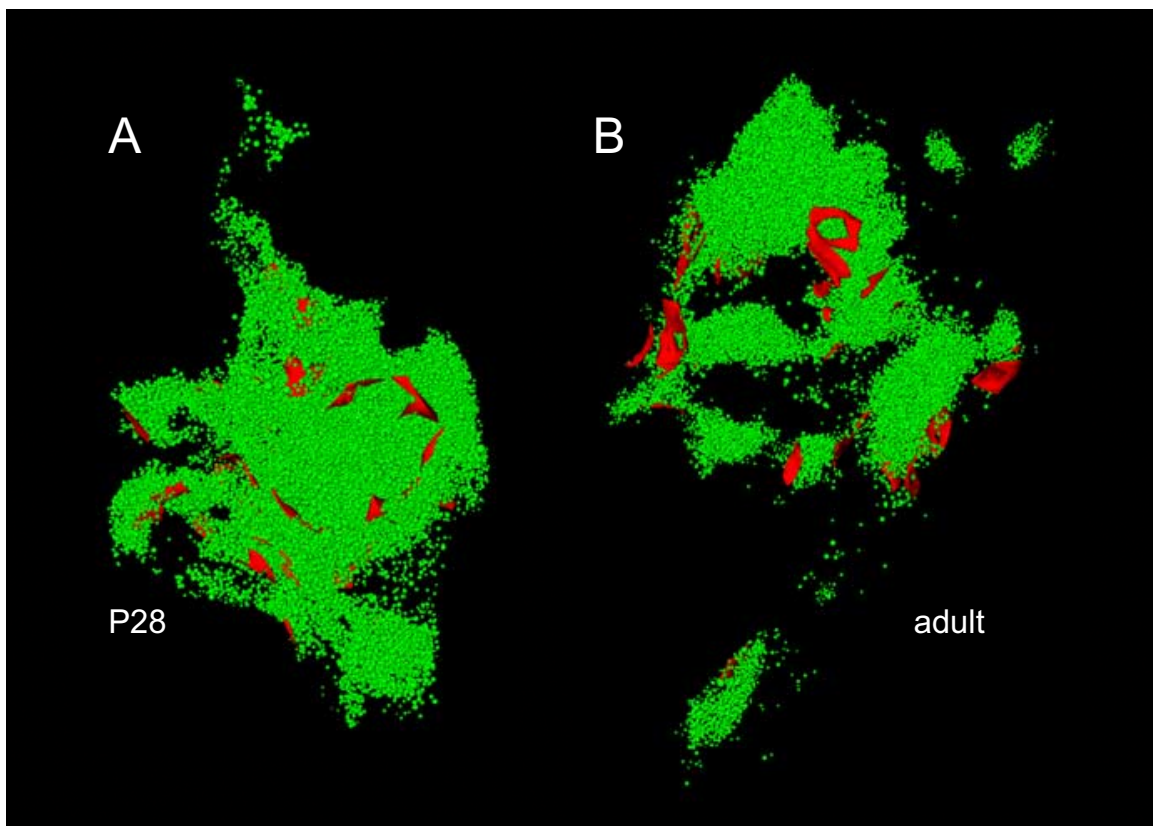

Figure 7. Comparison of the organization of the pool of synaptic vesicles between MFBs in P28 and adult rats. $\boldsymbol{A}, \boldsymbol{B}, 0$ rganization of the pool of synaptic vesicles (green dots). Here, two representative examples with a similar total pool size are given (P28, 25,683; adult, 25,028, respectively). In MFBs of P28 rats, no cluster-like arrangements of individual pools of synaptic vesicles around active zones (red) was observed. In contrast, individual pools of synaptic vesicles around a single or rows of AZs at spiny excrescences were frequently seen.

ganization of the pool of synaptic vesicles between MFBs in P28 and adult rats. Synaptic vesicles in young rats (P28) were evenly distributed throughout the terminal, thereby completely surrounding the spiny excrescences (Figs. $6 A, C, D, 7 A$ ). This distribution pattern may correspond to the functionally described "maxipool" of synaptic vesicles described by capacitance measurements of individual MFBs (Hallermann et al., 2003). In contrast, in the adult, synaptic vesicles were organized more in clusters of various sizes at individual AZs (Figs. 6B, 7B; supplemental movie, available at www.jneurosci.org as supplemental material) and/or a row of several AZs (Fig. 6G). In both ages, three different types of vesicles were found in MFBs: (1) small clear synaptic vesicles with a mean diameter of $31.70 \pm 6.00 \mathrm{~nm}$ for P28 and $31.20 \pm 5.20 \mathrm{~nm}$ for adult rats, ranging between 19.60 and 41.20 $\mathrm{nm}$ for individual boutons, (2) large clear vesicles (Henze et al., 2002a) ( $\geq 70 \mathrm{~nm}$ ) that constituted $\sim 1 \%$ of the total pool and were intermingled with the population of smaller synaptic vesicles, and (3) large dense-core vesicles. The mean number of large dense-core vesicles per bouton was $153.00 \pm 87.51$ (range, 43245) for P28 and 176.25 \pm 112.86 (range, 65-331) in adult rats, with an average diameter of $70.17 \pm 12.63$ and $61.50 \pm 4.35 \mathrm{~nm}$, respectively.

We attempted to identify subsets of synaptic vesicles as anatomical correlates for the three functional pools of releasable quanta of transmitter postulated from measurements of release rates. To define the RRP, the $\mathrm{RP}$, and the reserve pool morphologically, the number of synaptic vesicles within a perimeter of 60 $\mathrm{nm}$ ( $\sim 2$ vesicle diameters), $200 \mathrm{~nm}$ ( $\sim 5$ vesicle diameters), and $500 \mathrm{~nm}$ ( $\sim 15$ vesicle diameters $)$ was estimated (Fig. 8 B, Table 2 ) (for criteria, see also Rizzoli and Betz, 2004, 2005). The number of synaptic vesicles in each of the pools was clearly correlated with the size of individual AZs (Fig. 8A). Assuming a linear relationship between both measures, we can define a mean vesicle density for a given perimeter. The density of vesicles located within a distance of $100 \mathrm{~nm}$ from the active zone was $834 \mu \mathrm{m}^{-2}$ for P28 and $665 \mu \mathrm{m}^{-2}$ for adult MFBs. Thus, the density of synaptic vesicles at active zones in MFBs was about twofold higher than in the calyx of Held (Fig. 8A, dashed line).

The total pool of synaptic vesicles within individual large MFBs was on average $\sim 25,000$ (range, 11,000-49,000) in $\mathrm{P} 28$ and $\sim 16,000$ (range, $7600-25,000$ ) in adult rats (Table 1 ). In contrast, the number of synaptic vesicles in small filopodia was $\sim 200-700$, two orders of magnitude smaller than in the large boutons.

If the RRP is defined by $\sim 2$ vesicle diameters $(60 \mathrm{~nm})$, then the total RRP per large bouton was $\sim 1200$ vesicles (range, $\sim 350-2800)$ in $\mathrm{P} 28$ and $\sim 600$ vesicles (range, 370-1000) in adult rats, corresponding to $\sim 4 \%$ of the total pool of synaptic vesicles (Table 2). This corresponds to $36.66 \pm 18.17(\mathrm{P} 28, n=119 \mathrm{AZs})$ and $41.34 \pm 20.03$ (adult, $n=73$ AZs) vesicles per single AZs.

If the RP is defined by $\sim 5$ vesicle diameters, then the mean of the RP at individual MFBs is $\sim 5700$ (range, $1800-13,100$ ) vesicles ( $\sim 21 \%$ of the total pool) in P28 and $\sim 3700$ (range, 1500-4700) vesicles ( $\sim 20 \%$ of the total pool) in the adult. The relative size of the RP in the MFB is in good agreement with RP estimates reported for other synapses (Rizzoli and Betz, 2004, 2005). In both ages, the RRP and the RP showed a large variability, as indicated by the large SD and a consistently large CV of $\sim 1.0$. Despite the large $\mathrm{CV}$, the frequency distributions of the counts of synaptic vesicles were significantly different between P28 and adult in the range of 20-270 nm distance from the AZ ( $p \leq 0.05$, Kolmogorov-Smirnov test) (Fig. $8 B$ ). Furthermore, the RP of P28 or adult MFBs was fourfold to fivefold larger than at the calyx of Held (Fig. $8 B$, dashed line).

\section{Discussion}

Here, we describe for the first time the complete quantitative morphology and three-dimensional geometry of the hippocampal MFB. Our results suggest that the comparatively large size of $\mathrm{RRP}, \mathrm{RP}$, and reserve pool underlie the unique extent of synaptic efficacy and presynaptic plasticity of the hippocampal MF synapse. The quantitative structural data reported here also provide a basis for realistic models and numerical simulations of $\mathrm{MF}$ transmission, which may help to constrain functional parameters that are, at present, inaccessible experimentally.

\section{Size, number, and distribution of AZs}

The average surface area of an AZ in MFBs was $0.11 \mu \mathrm{m}^{2}$ (P28) and $0.13 \mu \mathrm{m}^{2}$ (adult), but a large variability in size and a skew toward small AZs was found (Fig. 4A, Table 1). The size of the AZ in MFBs was comparable with that in the calyx of Held in young rats $\left(0.10 \mu \mathrm{m}^{2}\right)$ (Sätzler et al., 2002) and adult deaf cats $(0.14$ $\mu \mathrm{m}^{2}$ ) (Ryugo et al., 1997), and with that in climbing fiber synapses $\left(0.14 \mu \mathrm{m}^{2}\right)$ (Xu-Friedman et al., 2001) and parallel fiber synapses of rat cerebellum $\left(0.13 \mu \mathrm{m}^{2}\right)$ (Xu-Friedman et al., 2001). However, AZs in MFBs were larger than those in the endbulb of Held in rats $\left(0.06 \mu \mathrm{m}^{2}\right)$ (Nicol and Walmsley, 2002), the 

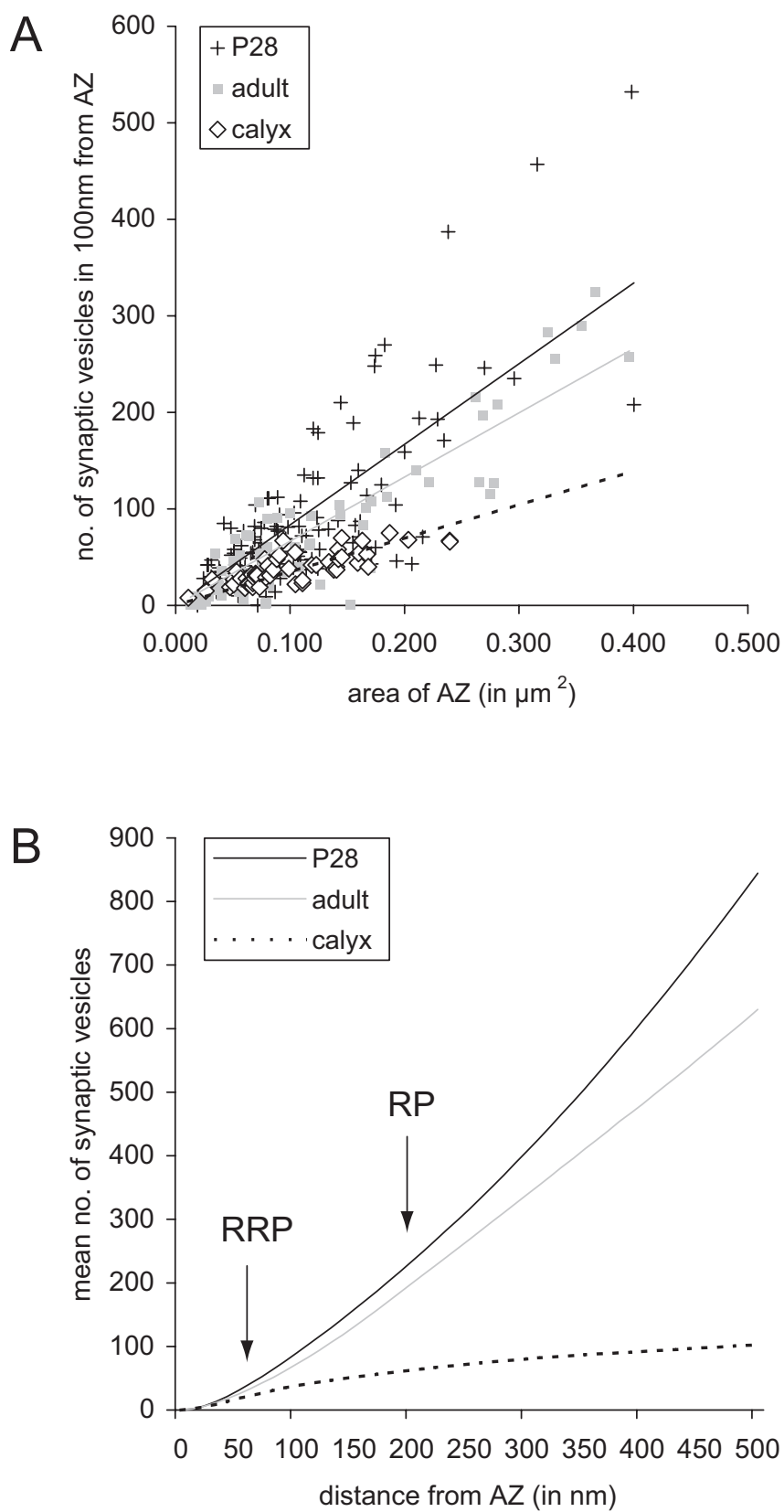

Figure 8. Number of synaptic vesicles per AZ. A, Scatter plot showing the relationship between the number of synaptic vesicles located within a perimeter of $100 \mathrm{~nm}$ from the AZ and the area of individual AZs for P28 MFBs (crosses), adult MFBs (gray circles), and the calyx of Held (open diamonds; included for comparison) (Sätzler et al., 2002). Data points were fitted by linear regression. The slope, corresponding to the average vesicle density, is slightly higher for P28MFBs $\left(834 \mu \mathrm{m}^{-2}\right.$ ) (black crosses and black solid line) than for the adult $\left(665 \mu \mathrm{m}^{-2}\right.$ ) (gray squares and gray solid line). For both P28 and adult MFBs, the slope is much larger than for the calyx $\left(349 \mu \mathrm{m}^{-2}\right)$ (open squares and black dashed line). Corresponding squares of correlation coefficients $\left(R^{2}\right)$ were $0.59,0.82$, and 0.51 for P28 MFB, adult MFB, and the calyx of Held, respectively. $\boldsymbol{B}$, The graph shows the correlation for the mean number of synaptic vesicles as a function of distance from an AZ (averaged over all AZs) for P28 MFBs (black line), adult MFBs (gray line), and the calyx of Held (dashed line) (Sätzler et al., 2002). The arrows indicate the borders between the RRP, the RP, and the reserve pool of synaptic vesicles. Note that the slope is markedly higher in the MFBs than the calyx, although the spacing between AZs is comparable at both synapses. This difference is significant for values beyond $50 \mathrm{~nm}$ ( $p \leq 0.05$ with the Kolmogorov-Smirnov test comparing the distance distributions for each perimeter; step size, $10 \mathrm{~nm}$ ). There is also a significant difference in the number of synaptic vesicles in MFBs of P28 versus adult rats within a perimeter of $20-270 \mathrm{~nm}(p \leq 0.05)$. calyx of Held in cats $\left(0.07 \mu \mathrm{m}^{2}\right)$ (Rowland et al., 2000), and glutamatergic synapses in the hippocampal CA1 region (0.06 $\mu \mathrm{m}^{2}$ ) (Harris and Stevens, 1989; Schikorski and Stevens, 2001; Marrone et al., 2005).

Whereas the size of the AZ in MFBs was similar to that in other central synapses, the number and density of AZs were substantially different. In our sample, the average number of AZs was 30 for P28 and 18 for adult MFBs, and the largest number of AZs found was 45 . Thus, the MFBs contained a large number of AZs (Chicurel and Harris, 1992), which covered on average $\sim 10 \%$ of the total surface area in which the postsynaptic target apposed the presynaptic terminal. In contrast, in the calyx of Held, $\sim 550 \mathrm{AZs}$ contributed only $\sim 5 \%$ to the apposition area between the presynaptic and postsynaptic membranes (Sätzler et al., 2002). Thus, AZs in MFBs covered a much larger fraction of the presynaptic surface area than in the calyx of Held. The density of AZs per bouton area in MFBs will be important for both synaptic strength of individual MFBs and input of multiple MFBs on the same postsynaptic CA3 pyramidal neuron (Fig. $1 B$ ), allowing convergence of $\sim 50$ MFBs on a single CA3 pyramidal neuron (Amaral and Dent, 1981).

Another functionally relevant structural factor is the spacing (nearest-neighbor relationship) of individual AZs, which is one possible determinant for spillover of transmitter and hence synaptic cross talk (Barbour and Häusser, 1997). In MFBs, the nearest-neighbor distance was on average $0.40 \mu \mathrm{m}$ (P28) and $0.48 \mu \mathrm{m}$ (adult), comparable with values estimated for the cerebellar MF synapse $(0.46 \mu \mathrm{m})$ (Xu-Friedman and Regehr, 2003), but different from the endbulb of Held $(0.15 \mu \mathrm{m})$ (Nicol and Walmsley, 2002) and the calyx of Held $(0.59 \mu \mathrm{m})$ (Sätzler et al., 2002) ( $p \leq 0.05$, Kolmogorov-Smirnov test). Because $80 \%$ of the distances between neighboring AZs were in the range between 0.20 and $0.60 \mu \mathrm{m}$ (Fig. $4 B$ ), our results indicate that cross talk may occur both presynaptically via diffusion of $\mathrm{Ca}^{2+}$ and postsynaptically via spillover of glutamate within the synaptic cleft, as proposed for the cerebellar MF synapses (DiGregorio et al., 2002).

\section{Location of PAs and glial coverage of individual MFBs}

An important structural difference between MFB and the calyx of Held was the arrangement of the two membrane specializations, AZs and PAs. In the MFB, AZs and PAs were clearly separated, with AZs located on the spiny excrescences and PAs exclusively found on the dendritic shafts (Fig. 2). In contrast, in the calyx of Held, PAs formed cluster-like arrangements between individual AZs that may isolate individual AZs from each other, thereby presumably preventing glutamate spillover and synaptic cross talk.

Another major difference to other central synapses was the glial ensheathment. In the MFB, astrocytes and their fine processes surrounded individual MFBs and their postsynaptic target dendrites, thereby isolating these synaptic complexes from adjacent MFBs and their targets (Figs. $1 B, 5$ ). In contrast, in other central synapses, fine glial processes were observed at the presynaptic and postsynaptic apposition zone (Xu-Friedman and Regehr, 2003) or even reached the synaptic cleft (Xu-Friedman et al., 2001) (for review, see Rollenhagen and Lübke, 2006). Because astrocytes act as physical barriers to glutamate diffusion and mediate transmitter uptake (e.g., by the glutamate transporters EAAT1 and EAAT2) (for review, see Danbolt, 2001; Oliet et al., 2004), the remote location of fine glial processes in the MFB may further enhance postsynaptic cross talk at hippocampal MF synapses (Barbour and Häusser, 1997). 
Table 2. Synaptic vesicle pools in MFBs

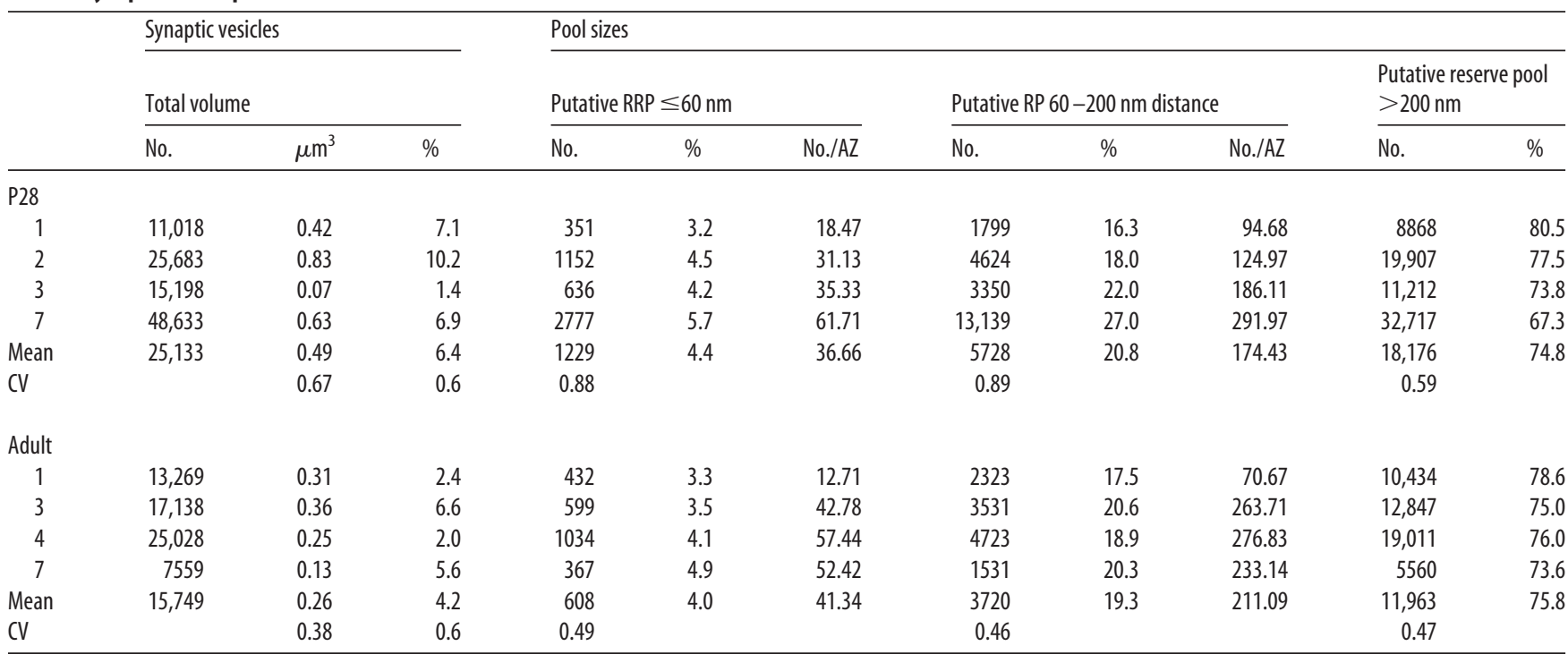

Summary of structural parameters relevant for release that have been extracted from the detailed 3-D reconstructions of MFBs in P28 and adult rats. For the RRP and RP, two values are given: the total number of synaptic vesicles per MFB and per individual AZ. For the reserve pool, the number of synaptic vesicles per bouton is given.

Thus, two structural factors are likely to promote cross talk at the MFB-CA3 pyramidal neuron synapse: (1) the short distance between adjacent AZs at spiny excrescences and (2) the absence of fine glial processes at and between AZs. Synaptic cross talk may prolong and amplify the synaptic current, contributing to the efficacy of hippocampal MF synapses.

\section{Size and organization of the vesicular pools}

Capacitance measurements at hippocampal MFBs revealed a large size of the releasable pool (maxipool) with $\sim 1400$ vesicles released during a $30 \mathrm{~ms}$ pulse (Hallermann et al., 2003). The present results show that the structural correlate of the releasable pool, although large, comprises only a small fraction of the total pool. Here, the total pool of synaptic vesicles was $\sim 25,000$ for P28 and $\sim 16,000$ vesicles for adult MFBs, distributed over 30 and 18 AZs, respectively. Thus, the total pool size of synaptic vesicles per $\mathrm{AZ}$ is $\sim 850$ in both ages. A very different scenario was found in the calyx of Held, in which $\sim 70,000$ vesicles were distributed over $\sim 550$ release sites with $\sim 125$ synaptic vesicles per AZ. In cerebellar MF synapses, fluctuation analysis of synaptic currents recently suggested a total pool size of 200,000 synaptic vesicles distributed over $\sim 330$ release sites (Saviane and Silver, 2006). Thus, the number of synaptic vesicles per AZ would be $\sim 600$ at cerebellar MF synapses. Interestingly, the total pool per AZ in the large MFB ( 900) appears to be larger than the pool in the endbulbs that emerge from filopodial extensions of the same terminal (200-700 vesicles per AZ). This may contribute to target cell-specific differences in synaptic dynamics (Tóth et al., 2000).

We subdivided the total pool of synaptic vesicles into three pools of vesicles located at a distance of $<60,60-200$, and $>200$ $\mathrm{nm}$ from the AZ, which may correspond to the RRP, the RP, and the reserve pool (Rosenmund and Stevens, 1996) (for review, see Rizzoli and Betz, 2004, 2005). The putative RRP size per MFB estimated with this criterion was $\sim 1200$ vesicles for P28 and $\sim 600$ vesicles for adult MFBs. Thus, the corresponding average $\mathrm{RRP}$ per release site $(\mathrm{AZ})$ was $\sim 41(\mathrm{P} 28)$ and $\sim 33$ in adult rats, respectively. A very different situation is found in the calyx of Held. Taking the $60 \mathrm{~nm}$ criterion, the total RRP at the calyx of Held was $\sim 10,000$ distributed over $\sim 550 \mathrm{AZs}$, equivalent to $\sim 18$ synaptic vesicles per AZ. Similarly, the putative RP was $\sim 5700$ vesicles for P28 MFBs, 3200 vesicles for adult MFBs, and $\sim 25,000$ for the calyx of Held. If estimated for individual AZs, the RP was fourfold larger in MFBs than in the calyx of Held. Finally, the putative reserve pool was $\sim 18,000$ vesicles for P28 MFBs, $\sim 12,000$ for adult MFBs, and $\sim 25,000$ for the calyx of Held. If estimated for individual AZs, the reserve pool was 10-fold larger in MFBs than in the calyx of Held (Fig. $8 B$ ). The large size of the $\mathrm{RRP}, \mathrm{RP}$, and reserve pool in each AZ may be a key structural correlate of presynaptic efficacy and plasticity at hippocampal MFBs (Salin et al., 1996; Geiger and Jonas, 2000).

\section{Functional significance}

Both the large number of release sites and the large size of RRP, $\mathrm{RP}$, and reserve pool will have important functional implications. The large number of release sites (AZs) together with the large RRP and RP will contribute to the high efficacy of the hippocampal MF synapse in vitro (Geiger and Jonas, 2000) and in vivo (Henze et al., 2002b) (for review, see Bischofberger et al., 2006). The high density of AZs at the presynaptic and postsynaptic apposition zone at the spiny excrescences is important to accommodate convergent input of multiple MFBs on the same postsynaptic CA3 pyramidal neuron (Amaral et al., 1990). The large RRP may prevent depletion during repetitive stimulation (e.g., if the animal is located in the center of the place field of a granule cell or during odor-guided behavioral tasks) (for review, see Bischofberger et al., 2006). However, even more importantly, the large size of RP and reserve pool could be used to rapidly refill the releasable pool if it has been depleted by long-lasting repetitive stimulation. If the refilling rates in MFBs were activity dependent, the large size of the RP could explain MF plasticity (e.g., the nearly 10 -fold increase in synaptic strength during frequency facilitation and posttetanic potentiation) (Salin et al., 1996). Thus, multiple structural determinants converge on the generation of a conditional detonator synapse.

\section{References}

Abercrombie M (1946) Estimation of nuclear population from microtome sections. Anat Rec 94:239-246.

Acsády L, Kamondi A, Sik A, Freund T, Buzsáki G (1998) GABAergic cells are the major postsynaptic targets of mossy fibers in the rat hippocampus. J Neurosci 18:3386-3403. 
Alle H, Geiger JR (2006) Combined analog and action potential coding in hippocampal mossy fibers. Science 311:1290-1293.

Amaral DG, Dent JA (1981) Development of the mossy fibers of the dentate gyrus: I. A light and electron microscopic study of the mossy fibers and their expansions. J Comp Neurol 195:51-86.

Amaral DG, Ishizuka N, Claiborne B (1990) Neurons, numbers and the hippocampal network. Prog Brain Res 83:1-11.

Barbour B, Häusser M (1997) Intersynaptic diffusion of neurotransmitter. Trends Neurosci 20:377-384.

Bischofberger J, Geiger JR, Jonas P (2002) Timing and efficacy of $\mathrm{Ca}^{2+}$ channel activation in hippocampal mossy fiber boutons. J Neurosci 22:10593-10602.

Bischofberger J, Engel D, Frotscher M, Jonas P (2006) Timing and efficacy of transmitter release at mossy fiber synapses in the hippocampal network. Pflügers Arch 453:361-372.

Blackstad TW, Kjaerheim A (1961) Special axo-dendritic synapses in the hippocampal cortex: electron and light microscopic studies on the layer of mossy fibers. J Comp Neurol 117:133-159.

Chicurel ME, Harris KM (1992) Three-dimensional analysis of the structure and composition of CA3 branched dendritic spines and their synaptic relationships with mossy fiber boutons in the rat hippocampus. J Comp Neurol 325:169-182.

Danbolt NC (2001) Glutamate uptake. Prog Neurobiol 65:1-105.

Derouiche A, Frotscher M (1991) Astroglial processes around identified glutamatergic synapses contain glutamine synthetase: evidence for transmitter degradation. Brain Res 552:346-350.

DiGregorio DA, Nusser Z, Silver RA (2002) Spillover of glutamate onto synaptic AMPA receptors enhances fast transmission at a cerebellar synapse. Neuron 35:521-533.

Engel D, Jonas P (2005) Presynaptic action potential amplification by voltage-gated $\mathrm{Na}^{+}$channels in hippocampal mossy fiber boutons. Neuron 45:405-417.

Frotscher M, Soriano E, Misgeld U (1994) Divergence of hippocampal mossy fibers. Synapse 16:148-160.

Frotscher M, Jonas P, Sloviter RS (2006) Synapses formed by normal and abnormal hippocampal mossy fibers. Cell Tissue Res 326:361-367.

Galimberti I, Gogolla N, Alberi S, Santos AF, Muller D, Caroni P (2006) Long-term rearrangements of hippocampal mossy fiber terminal connectivity in the adult regulated by experience. Neuron 50:749-763.

Geiger JR, Jonas P (2000) Dynamic control of presynaptic $\mathrm{Ca}^{2+}$ inflow by fast-inactivating $\mathrm{K}^{+}$channels in hippocampal mossy fiber boutons. Neuron 28:927-939.

Hallermann S, Pawlu C, Jonas P, Heckmann M (2003) A large pool of releasable vesicles in a cortical glutamatergic synapse. Proc Natl Acad Sci USA 100:8975-8980.

Hamlyn LH (1962) The fine structure of the mossy fibre endings in the hippocampus of the rabbit. J Anat 96:112-120.

Harris KM, Stevens JK (1989) Dendritic spines of CA 1 pyramidal cells in the rat hippocampus: serial electron microscopy with reference to their biophysical characteristics. J Neurosci 9:2982-2997.

Henze DA, McMahon DB, Harris KM, Barrionuevo G (2002a) Giant miniature EPSCs at the hippocampal mossy fiber to CA3 pyramidal cell synapse are monoquantal. J Neurophysiol 87:15-29.

Henze DA, Wittner L, Buzsáki G (2002b) Single granule cells reliably discharge targets in the hippocampal CA3 network in vivo. Nat Neurosci 5:790-795.

Honda T, Sakisaka T, Yamada T, Kumazawa N, Hoshino T, Kajita M, Kayahara T, Ishizaki H, Tanaka-Okamoto M, Mizoguchi A, Manabe T, Miyoshi J, Takai Y (2006) Involvement of nectins in the formation of puncta adherentia junctions and the mossy fiber trajectory in the mouse hippocampus. Mol Cell Neurosci 31:315-325.

Kobayashi K, Poo MM (2004) Spike train timing-dependent associative modification of hippocampal CA3 recurrent synapses by mossy fibers. Neuron 41:445-454.

Lawrence JJ, Grinspan ZM, McBain CJ (2004) Quantal transmission at mossy fibre targets in the CA3 region of the rat hippocampus. J Physiol (Lond) 554:175-193.

Lisman JE (1999) Relating hippocampal circuitry to function: recall of memory sequences by reciprocal dentate-CA3 interactions. Neuron $22: 233-242$
Marrone DF, LeBoutillier JC, Petit TL (2005) Ultrastructural correlates of vesicular docking in the rat dentate gyrus. Neurosci Lett 378:92-97.

Nicol MJ, Walmsley B (2002) Ultrastructural basis of synaptic transmission between endbulbs of Held and bushy cells in the rat cochlear nucleus. J Physiol (Lond) 539:713-723.

Nicoll RA, Schmitz D (2005) Synaptic plasticity at hippocampal mossy fibre synapses. Nat Rev Neurosci 6:863-876.

Oliet SH, Piet R, Poulain DA, Theodosis DT (2004) Glial modulation of synaptic transmission: insights from the supraoptic nucleus of the hypothalamus. Glia 47:258-267.

R Development Core Team (2005) R: a language and environment for statistical computing. Vienna: R Foundation for Statistical Computing.

Rizzoli SO, Betz WJ (2004) The structural organization of the readily releasable pool of synaptic vesicles. Science 303:2037-2039.

Rizzoli SO, Betz WJ (2005) Synaptic vesicle pools. Nat Rev Neurosci 6:57-69.

Rizzuto R, Bernardi P, Pozzan T (2000) Mitochondria as all-round players of the calcium game. J Physiol (Lond) 529:37-47.

Rollenhagen A, Lübke JHR (2006) The morphology of excitatory central synapses: from structure to function. Cell Tissue Res 326:221-237.

Rosenmund C, Stevens CF (1996) Definition of the readily releasable pool of vesicles at hippocampal synapses. Neuron 16:1197-1207.

Rostaing P, Real E, Siksou L, Lechaire JP, Boudier T, Boeckers TM, Gertler F, Gundelfinger ED, Triller A, Marty S (2006) Analysis of synaptic ultrastructure without fixative using high-pressure freezing and tomography. Eur J Neurosci 24:3463-3474.

Rowland KC, Irby NK, Spirou GA (2000) Specialized synapse-associated structures within the calyx of Held. J Neurosci 20:9135-9144.

Ryugo DK, Pongstaporn T, Huchton DM, Niparko JK (1997) Ultrastructural analysis of primary endings in deaf white cats: morphologic alterations in endbulbs of Held. J Comp Neurol 385:230-244.

Sahara Y, Takahashi T (2001) Quantal components of the excitatory postsynaptic currents at a rat central auditory synapse. J Physiol (Lond) 536:189-197.

Salin PA, Scanziani M, Malenka RC, Nicoll RA (1996) Distinct short-term plasticity at two excitatory synapses in the hippocampus. Proc Natl Acad Sci USA 93:13304-13309.

Sätzler K, Söhl LF, Bollmann JH, Borst JG, Frotscher M, Sakmann B, Lübke JHR (2002) Three-dimensional reconstruction of a calyx of Held and its postsynaptic principal neuron in the medial nucleus of the trapezoid body. J Neurosci 22:10567-10579.

Saviane C, Silver RA (2006) Fast vesicle reloading and a large pool sustain high bandwidth transmission at a central synapse. Nature 439:983-987.

Schikorski T, Stevens CF (2001) Morphological correlates of functionally defined synaptic vesicle populations. Nat Neurosci 4:391-395.

Schneggenburger R, Meyer AC, Neher E (1999) Released fraction and total size of a pool of immediately available transmitter quanta at a calyx synapse. Neuron 23:399-409.

Schneggenburger R, Sakaba T, Neher E (2002) Vesicle pools and short-term synaptic depression: lessons from a large synapse. Trends Neurosci 25:206-212.

Sun JY, Wu LG (2001) Fast kinetics of exocytosis revealed by simultaneous measurements of presynaptic capacitance and postsynaptic currents at a central synapse. Neuron 30:171-182.

Tóth K, Suares G, Lawrence JJ, Philips-Tansey E, McBain CJ (2000) Differential mechanisms of transmission at three types of mossy fiber synapse. J Neurosci 20:8279-8289.

Verstreken P, Ly CV, Venken KJ, Koh TW, Zhou Y, Bellen HJ (2005) Synaptic mitochondria are critical for mobilization of reserve pool vesicles at Drosophila neuromuscular junctions. Neuron 47:365-378.

Wimmer VC, Horstmann H, Groh A, Kuner T (2006) Donut-like topology of synaptic vesicles with a central cluster of mitochondria wrapped into membrane protrusions: a novel structure-function module of the adult calyx of Held. J Neurosci 26:109-116.

Xu-Friedman MA, Regehr WG (2003) Ultrastructural contributions to desensitization at cerebellar mossy fiber to granule cell synapses. J Neurosci 23:2182-2192.

Xu-Friedman MA, Harris KM, Regehr WG (2001) Three-dimensional comparison of ultrastructural characteristics at depressing and facilitating synapses onto cerebellar Purkinje cells. J Neurosci 21:6666-6672. 